\title{
NI VÍCTIMXS, NI PASIVXS, SÍ COMBATIVXS. VISUALIDADES FEMINISTAS, AUTORREPRESENTACIÓN DE CUERPOS EN LUCHA
}

\author{
Julia Antivilo Peña
}




\section{JULIA ANTIVILO PEÑA}

Historiadora y artivista performancera feminista (Huasco, Chile, 1974). Ha escrito los libros Belén de Sárraga. Precursora del feminismo hispanoamericano, junto a Luis Vitale (2000), y Entre lo sagrado y lo profano se tejen rebeldías. Arte feminista latinoamericano (2015), entre otros. También es autora de varios artículos en revistas sobre estudios culturales, el papel social y cultural de las mujeres y arte, géneros y feminismos. Es doctora en Estudios Culturales Latinoamericanos de la Universidad de Chile y recientemente terminó una investigación posdoctoral sobre artivismo y disidencia sexual en América Latina (Universidad Autónoma Metropolitana, México). Además, como performancera ha sido parte de varios colectivos artivistas feministas en Chile y México. Se ha presentado en eventos académicos y artísticos en países como Chile, Argentina, Bolivia, Colombia, Uruguay, Costa Rica, Cuba, México, EE.UU, Canadá e Italia. Reside en México y colabora con los grupos de arte (y con sus archivos) La Pocha Nostra, Pinto mi Raya y Producciones y Milagros Agrupación Feminista A.C. Además, forma parte de la colectiva Laboratorio Curatorial Feminista y de la Red Conceptualismo del Sur. 


\section{NI VÍCTIMXS, NI PASIVXS, SÍ COMBATIVXS. VISUALIDADES FEMINISTAS, AUTORREPRESENTACIÓN DE CUERPOS EN LUCHA}

\section{PALABRAS PRELIMINARES}

Desde su emergencia en los años '60 en América Latina, el arte feminista ha centrado su objetivo en cuestionar la representación de las identidades marginadas y en sacar a la luz las estructuras patriarcales impuestas. Estos actos artísticos han sido una lucha política en favor de la visibilidad y la igualdad. La construcción cultural del cuerpo, entendido como algo natural y depositario de las divisiones sociales entre los sexos, fue el esquema a romper por parte de muchas de lxs artistas feministas activistas. Para ello buscaron y crean todavía nuevos lugares de resistencia en los que romper con los dualismos occidentales (masculino-femenino, sujeto-objeto, público-privado, activo-pasivo), donde la interrelación entre diferentes grupos fuese posible, donde se compartiesen experiencias y la reciprocidad fuese parte del proceso creativo. El arte feminista, entre otras cosas, se propuso cambiar el cuerpo femenino al cuerpo de las mujeres, o sea, de objeto pasivo a agente comunicativo, significante y diverso. Ese camino lo ha hecho junto a todas las disidencias sexuales.

A partir de la propuesta político estética-feminista, las artistas visuales y artivistas feministas intentan la deconstrucción de la cultura patriarcal capitalista, generando nuevos significantes históricos y sociales a través de las visualidades y sus cuerpos en lucha.

Los albores del feminismo como movimiento social y corriente de pensamiento político iniciaron en el siglo XIX, vinculados al movimiento obrero y al sufragismo más tarde, razón por la que no tardaran en aparecer cuestionamientos dentro del movimiento por las diferencias de clase. A finales de la primera mitad del siglo XX, debido a la cooptación de mujeres por los partidos políticos principalmente de izquierda y de otros movimientos sociales, tales como el obrero o de pobladores, el feminismo se fragmentó cuando se superaron, en parte, algunas de las discriminaciones que históricamente habían sufrido las mujeres (desigualdad en los derechos políticos y sociales, tales como el derecho a la educación y el voto). Tras la Segunda Guerra Mundial, que provocó un retroceso en el reconocimiento de los derechos ganados por muchas mujeres, las reivindicaciones resurgieron con fuerza, cristalizando en los "70 la llamada "nueva ola" del feminismo junto a las disidencias sexuales. Entre las reivindicaciones que se tornaron grito de guerra 
estaban la liberación sexual y emancipación de las mujeres del llamado tercer mundo, las cuales denunciaban la discriminación por clase, género y raza; exigían el derecho a una sexualidad libre, al divorcio, al aborto y a la igualdad de la mujer en la unidad familiar ante la ley, rechazando la subordinación económica (brecha salarial entre los géneros), especialmente en los países más pobres. Muchas de estas reivindicaciones del feminismo actualmente se mantienen. Si bien el siglo XX trajo varios avances, como los logros en los derechos civiles, por ejemplo, el cambio de siglo vislumbró un movimiento, en palabras de Francesca Gargallo, que vivía:

"en sus diferencias internas. Es un movimiento de movimientos, algunas veces en
diálogo, otras enfrentados, la mayoría de las veces desconociéndose mutuamente.
Esta condición hace revivir la importancia de las definiciones conceptuales y de
las prácticas que conllevan. Hoy en día, vuelve a ser fundamental el análisis de
qué es lo universal y, si existe, de cómo vivir la propia diferencia, cuáles son los
límites a la aceptación de la pluralidad, a las diferencias y, por lo mismo, qué
contrastes son los que permiten la relación política con el pensamiento, para no
caer en el pluralismo entendido como un estar juntas sin un motivo válido para
esta unión" (2004:109).

A pesar de este panorama, muy similar a lo que pasa en otros movimientos sociales, la creatividad feminista se muestra con nuevos bríos colectivos desde la segunda década del siglo XXI y persiste ya sea como escaramuza y/o en movimiento, y continúa marcando la misma ruptura como arte político, tal como lo inició en los años ${ }^{6} 70$.

El arte feminista es una expresión de un arte político y vanguardista que emerge en los ' 70 , consolida su praxis en los ' 80 y proyecta renovados aires bajo el contexto del neoliberalismo (desde la década del ' 90 hasta la actualidad de este nuevo viejo orden económico, social y cultural). Es un neoliberalismo que sólo en lo económico es liberal desatado, pues en todo lo demás es más bien neoconservador y neocolonizador. Se trata de una corriente que no sólo sigue basando las economías en la exportación de materias primas sino que las refuerza con mano de obra barata migrante o tal como lo llama María Galindo, artista y activista feminista boliviana, con los y las exiliadas del neoliberalismo ${ }^{1}$.

Consideramos que la producción artivista se debe entender como una práctica política estética que trabaja en lo social y cultural. De ahí que las visualidades feministas hoy gozan de la plenitud de la vida, con más de cuarenta años de creación

1. Ver en texto del mismo nombre en la web http://www.mujerescreando.org 
visual con marcada desobediencia de las condiciones generales de producción social y cultural dominante.

Las políticas de autorrepresentación definen muchas cosas, como por ejemplo, qué queremos decir con una imagen, qué comprometemos en ella, qué valores queremos transmitir, etc. Es por esto que desde que hemos logrado tener voces y visibilidad desde los feminismos y la disidencia sexual, tenemos responsabilidad en la producción de las visualidades que promovemos como nuestras banderas o denuncias, o resistencias, entre muchas más. Por ello, a través de este escrito me propongo reflexionar en torno a las visualidades feministas en América Latina a lo largo de su historia con el fin de pensarnos hoy en esta nueva ola feminista que vivimos.

\section{PONER EL CUERPO A LA AUTORREPRESENTACIÓN}

Entiendo por visualidades los productos de las tecnologías visuales que se producen en la cultura como campo transdisciplinario y que se perciben en la historia del arte, de la cultura, el cine o el periodismo y la sociología, en tanto acontecimientos visuales en los que las personas buscan información, el significado o el placer visual en tecnologías visuales, es decir, y citando al precursor del campo de la cultura visual Nicholas Mirzoeff, los generados por "cualquier forma de aparato diseñado ya sea para ser observado o para aumentar la visión natural, desde la pintura al óleo hasta la televisión e Internet" (2003:19). Si bien este concepto nace para abordar un campo en un tiempo determinado, lo podemos sacar de contexto para el caso de los feminismos, que son productores de visualidades que caracterizan su forma de ponerle el cuerpo a su política con una estética muy creativa que va desde los pañuelos morados bordados de las decimonónicas sufragistas inglesas que inscribían los nombres de las presas políticas, pasando por las mexicanas bordadoras de feminicidios, hasta los pañuelos verdes por la lucha del aborto de las argentinas que hoy en día que se han propagado a Chile, Brasil y México.

Así, la producción de las artivistas feministas en América Latina se puede aprehender más fácilmente desde los estudios de la cultura visual que desde la historia del arte, que la ha excluido desde su emergencia. Además, considero que con los fines políticos que busca el arte feminista le es más interesante incidir en la cultura y en la cotidianeidad que en la historia del arte mismo, pues esta última disciplina casi sólo se piensa sin una vinculación con lo social.

Por lo anterior, la producción del artivismo feminista desde las visualidades impacta en la cultura visual de Latinoamérica, pues como discurso posee una agudeza en el campo de la subversión de todo el esquema de representación androcéntrica. 
Constituye una vindicación de un territorio para la autorrepresentación de las identidades. Conscientes del peso que significa la cultura visual en el mundo y en especial en esta región, muchxs artistas han utilizado formatos fuera de lo usualmente artístico para hacer presente la producción artivista feminista. La colectiva de arte feminista argentina Mujeres Públicas hizo varias intervenciones a las paletas publicitarias de la ciudad de Buenos Aires durante los años 2003 y 2004. Las acciones consistían en adherir globos de textos y/o pintar stencils, dando voz de subversión feminista a las y los modelos que como maniquíes de la belleza occidental, blanca y heterosexual nos entrega la publicidad, denotando todo su sexismo, clasismo y racismo. Los globos de textos y stencils tenían como frase fija Esta Belleza. A ella se le incorporaban las siguientes expresiones: me oprime, castiga, discrimina, deforma, subestima, condiciona, reprime, controla, oprime, lastima, enferma, entre otras.

Otro ejemplo de intervención de artistas feministas en la cultura visual son las grafiteadas de las bolivianas de Mujeres Creando. Estas artivistas se han apropiado desde la década del '90 de los muros de La Paz, en los cuales inscriben acciones poéticas que visten y desvisten la ciudad. A través de cada trazo de pintura y letra cursiva, grafitean la realidad de las mujeres y sus críticas al Estado boliviano, al heterocapitalismo y a las diversas coyunturas políticas que le hacen frente. Algunas de sus grafiteadas dicen:

- Elpríncipe azul no existe, el macho violento sí, cuídate!!

- Nuestros sueños son sus pesadillas.

- Es justo y necesario que este cuerpo mío sea siempre mío.

- Desobediencia, por tu culpa voy a ser feliz.

- No bay nada más parecido a un machista de derechas que un machista de izquierdas y un indígena: la misma pistola. 
Fotos 1 y 2. Mujeres Creando, grafiti en La Paz, Bolivia
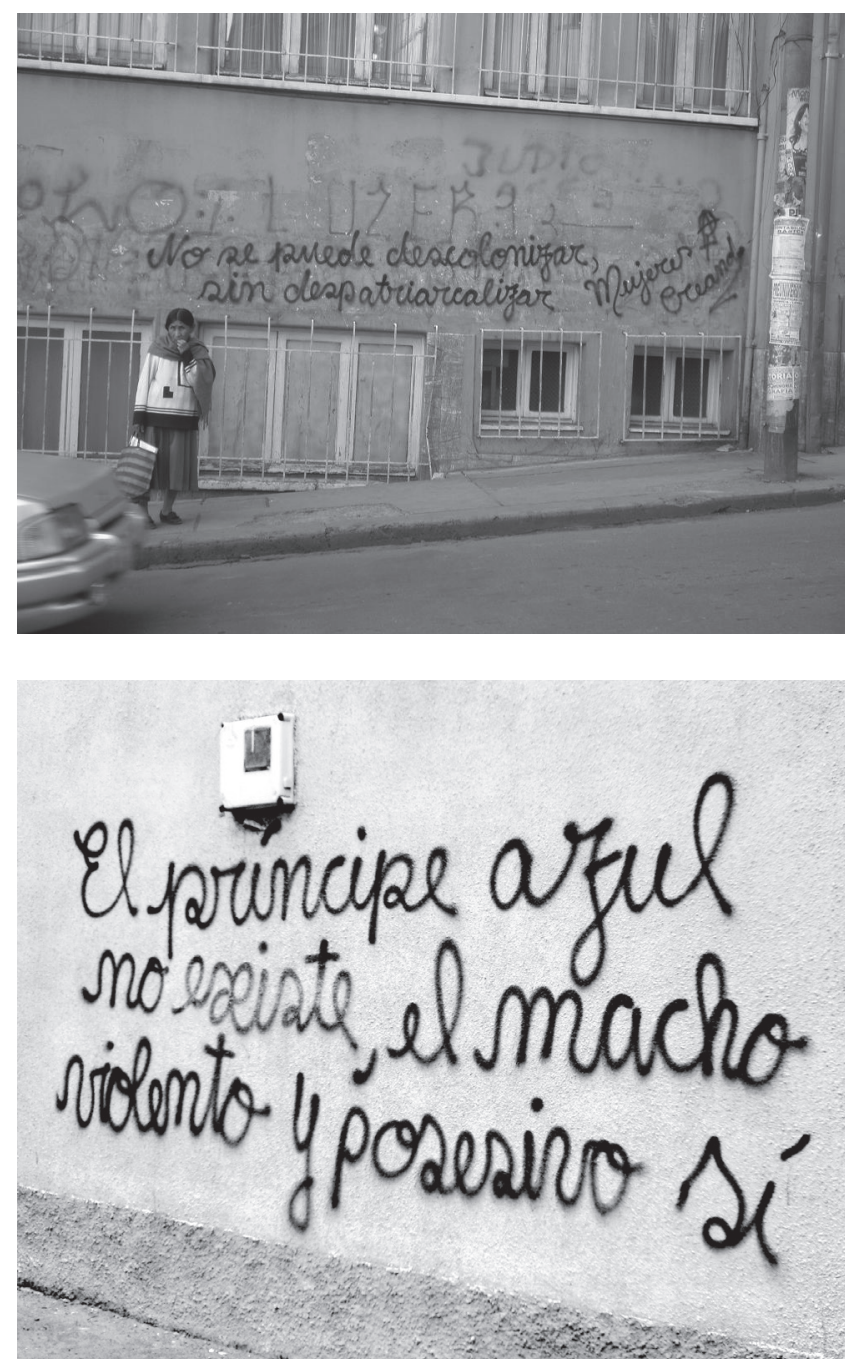

Fotografías: Idoia Romano. Archivo de Mujeres Creando

Otra artista feminista surgida en la década del ' 90 y activa hasta hoy en día es la mexicana Lorena Wolffer, quien ha inscrito su discurso visual feminista a través de soportes propios de la publicidad. En la obra llamada "Soy Totalmente de Hierro" parafrasea el lema comercial de una tienda de departamentos de México llamada El Palacio de Hierro, que tiene como eslogan la frase "Soy Totalmente Palacio". Entonces la subvierte para hablarnos de la violencia sexista que lleva implícita la publicidad y la violencia cotidiana hacia las mujeres en la vida citadina, por ejemplo en el 
transporte, la calle, etc. La obra consistió en instalar diez gigantografías, o también llamados espectaculares, a modo de contra campaña publicitaria en distintos puntos de la Ciudad de México. Para la artista, "Las obras se valían de retóricas antagónicas y opuestas a las empleadas en 'Soy Totalmente Palacio', generando así un espacio 'publicitario' alterno que invitaba al análisis de las intrincadas formas en las que la sociedad -a través de uno de sus medios más contundentes y reveladores- construye y manipula nuestras nociones de feminidad"2. Los espectaculares se exhibieron del 1 de julio al 30 de agosto de 2000 en Tlalpan y Eje 6 Sur; Periférico Canal de Garay y Eje 6 Sur; San Antonio Abad, Plaza Santa Cruz; Insurgentes y Avenida del Imán; Insurgentes y Copilco; Insurgentes y Quintana Roo; Avenida Santa Teresa, Pedregal del Lago; Río Churubusco y Calle 17; Periférico Sur y Zacatépetl; y Viaducto y Tránsito en México D.F. Cabe mencionar que todas las intersecciones de las calles en las que se ubicaron las gigantografías tienen una muy alta afluencia de personas diariamente. Por lo tanto, la incidencia de esta intervención fue semejante a la que produce una publicidad, pero en este caso con el objetivo visibilizar un tema tan grave en México como lo es la violencia machista.

Foto 3. Lorena Wolffer, Soy Totalmente de Hierro, México, 2000

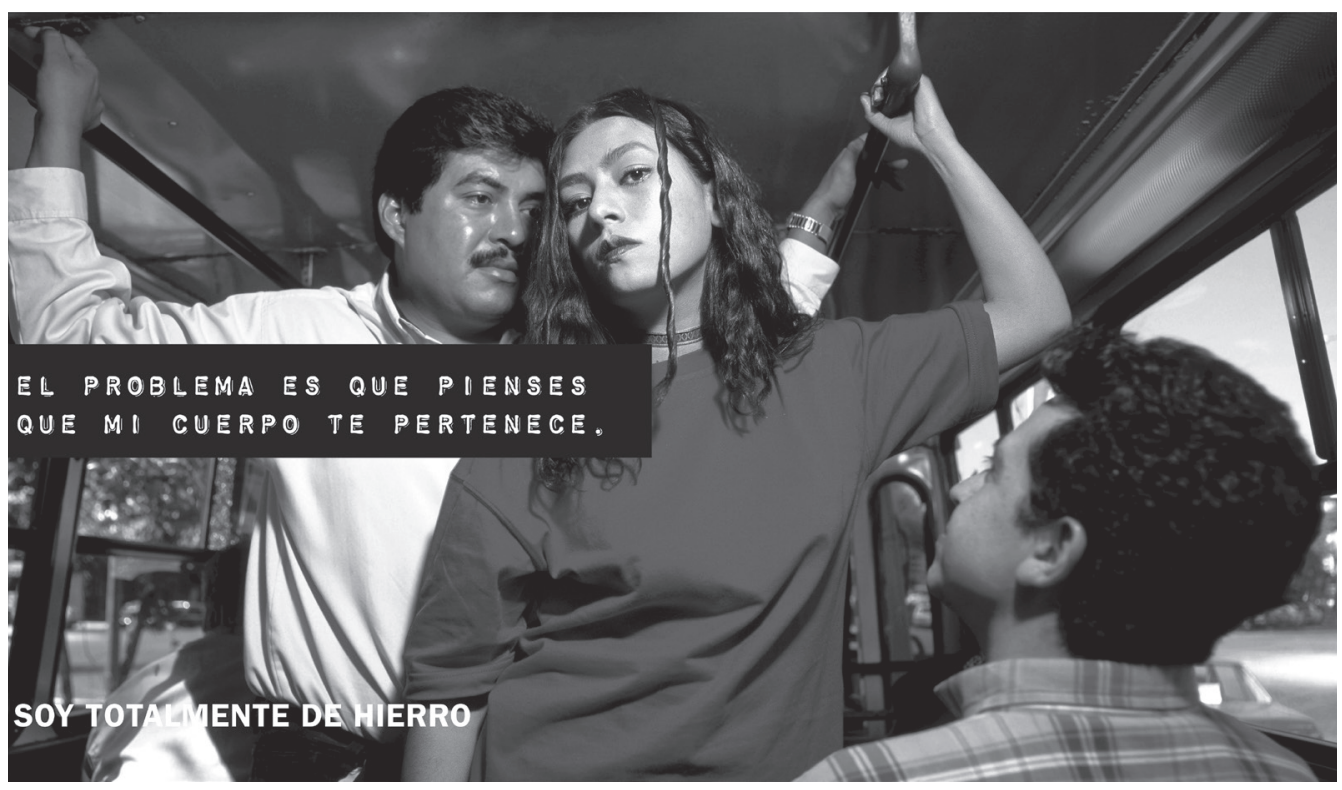

Fotografía: gentileza de la artista

2. Ver más en http://www.lorenawolffer.net 
Con un pie en el arte político y otro en el activismo, las visualidades feministas se han manifestado performativamente durante más de cuatro décadas en América Latina. Una pionera es María Luisa Bemberg' con el cortometraje "El mundo de la mujer", realización visual crítica a la exposición llamada "Femimundo "72. Exposición internacional de la mujer y su mundo", una especie de "feria de la mujer moderna" que se llevó a cabo en la ciudad de Buenos Aires (1972). Bemberg, militante de la Unión Feminista Argentina (UFA) y una de sus fundadoras, registró con su lente feminista el activismo de UFA al interior de ella. Documenta la distribución de volantes que desarrollaba UFA en este evento de carácter sexista. El registro viene acompañado de una sarcástica narración que combina la voz oficial de la feria y textos seleccionados del Libro azul, de Para ti y de la Guía para saber cuál es la mujer ideal para cada hombre, cómo debe hacer para conquistarlo y conservar el amor. Ambos eran manuales de cómo ser mujer en una sociedad patriarcal. Además, la cineasta inserta música de películas y ciertos textos del cuento La Cenicienta. María Laura Rosa nos relata que:

"A primera vista Bemberg exhibe la construcción de un ideal de mujer moldeada por el patriarcado para la felicidad del varón. En su papel servicial y procreador, la mujer se encuentra atrapada en un entramado en el cual la publicidad y el consumo contribuyen a legitimar e imponer. A partir de un amplio recorrido por la exposición, el ojo de Bemberg va mostrando cómo se difunde un modelo de dominación, normalización, vigilancia y control sobre el cuerpo y el espíritu de las mujeres, el cual se naturaliza a través del orden del lenguaje y del visual" (2010).

La cámara, señala Clara Fontana, "revolotea todo el tiempo entre electrodomésticos, desfiles de modas y peinados y aparatos surrealistas destinados a la belleza y al confort. Toda esta parafernalia de uso esencialmente doméstico es presentada con ironía y a menudo con irritación" (1993:19).

El corto fue acompañado con actividades de reflexión en diferentes espacios que fueron desde escuelas a iglesias evangélicas hasta casas particulares, pasando por asociaciones. "El mundo de la mujer" marca otra característica que veremos en

3. Buenos Aires, 1922-1995. Ver más en http://www.marialuisabemberg.com

4. El mundo de la mujer. Dirección: María Luisa Bemberg. Jefe de Producción: María Rosa Sichel. Sonido: Nerio Barberis. Cámara: Osvaldo Fiorino. Editor: Miguel Pérez. Año: 1972. Duración: 15'45”. Ver en http://www.marialuisabemberg.com/cortos.php 
la praxis de las artistas visuales que toman la militancia de su arte y la difunden a través de instancias que buscan fines didácticos y pedagógicos.

En la década del '80, dos mega eventos conforman los hitos de un arte feminista consolidado. Uno de ellos fue "La fiesta de los XV años” (Ciudad de México, 1984), organizado por la colectiva feminista Tlacuilas y Retrateras ${ }^{5}$, y el otro, "Mitominas" (1986 y 1988, Buenos Aires), desarrollado por una veintena de artistas feministas. Ambos eventos ponen en evidencia que el sujeto "mujer" se construye en el discurso y en la representación, por tanto, no es una categoría fija y estable. Además inscriben en la historia patriarcal y en el arte, como pedagogía visual, la responsabilidad de la construcción de los géneros. Los dos eventos postulaban una revisión crítica de los imaginarios culturales sobre las mujeres latinoamericanas y tuvieron amplias coberturas en la prensa y un numeroso público.

Por otra parte, cierran la década la deliciosa irreverencia marica de las Yeguas del Apocalipsis, quienes a través de sus performances remecieron la escena artivista en un Chile que cerraba el capítulo más funesto de su historia tras años de dictadura militar.

A finales de los '90, acciones performáticas son parte del Primer Encuentro de Mujeres Libertarias realizado en El Pinar, localidad ubicada cerca de Montevideo. Varios colectivos feministas, tales como Mujeres Creando de Bolivia, Las Clorindas de Chile, Las Tendiras y Las Decidoras de Uruguay, Las Mujeres Libres de Argentina y muchas más feministas sueltas de Brasil, España y de los países ya nombrados, se reunieron en el último taller del encuentro, dedicado al cuerpo. El contexto histórico que se vivía nos mostraba, en vivo y en directo por la televisión, la extrema situación que pasaba el pueblo afgano bajo el régimen talibán. En pocos meses desde su ascensión, habían arreciado las prohibiciones contra las acciones de las mujeres en lo público y se las condenaba a moverse en las calles como fantasmas, avanzando rozando las paredes en grupos de dos o de tres, ocultas bajo el chadri o burka, un velo total que sólo deja pasar su mirada a través de una rejilla de tela. También tenían prohibición de trabajar fuera de casa, de estudiar, de recibir atención médica, o sea, de todos los derechos civiles básicos.

En solidaridad, como una forma de denunciar esa realidad y como cierre de este encuentro de feministas libertarias, se organizó una gran marcha por varias calles de Montevideo en dirección a Plaza Cagancha, lugar significativo de las movilizaciones sociales de esa capital que se ubica frente a los Tribunales de Justicia. Todas marchamos vestidas con burkas que nos habíamos confeccionado con bolsas de basura para simbolizar en ese atuendo obligatorio nuestro repudio al

5. Ver más en https://es.wikipedia.org/wiki/Tlacuilas_y_Retrateras. 
régimen feminicida y la cárcel que llevaban a cuestas las afganas. Cuando llegamos frente a los Tribunales de Justicia de la capital uruguaya, un grupo de nosotras de diferentes nacionalidades realizamos un minuto de desnudez liberadora por la violencia machista del otro lado del mundo. Fue una protesta atípica que quedó registrada como portada de varios diarios montevideanos y las mujeres incluso fueron invitadas a un programa de conversación de la televisión local.

\section{Foto 4. Portada del diario La República, 9 de febrero de 1999, Montevideo}

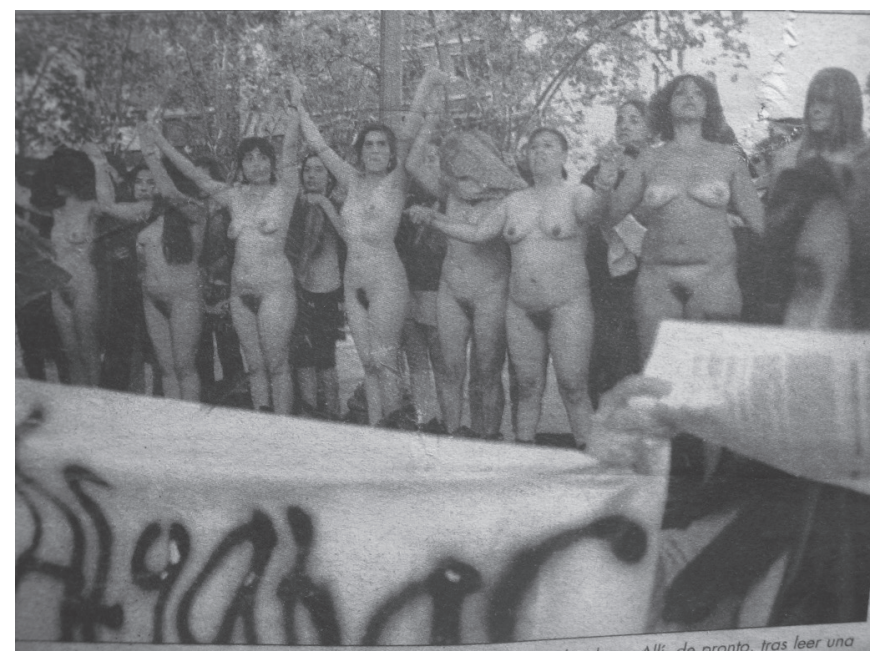

En el marco de las protestas ciudadanas por la prohibición de la pastilla de emergencia en Chile (2008) surgió el colectivo clandestino Las Choras del Puerto, grupo de performanceras y artistas de la gráfica digital de Valparaíso que se definieron en su manifiesto al ritmo del rap como "Brujas, locas, camboyanas, histéricas, warriors, putas, marías tres cocos, amazonas, marimachas, vírgenes, guerreras, chulas, tránsfugas, lesbianas, trans, pulguitas en tu oreja, palitos en tu poto, hinchapelotas, descarriadas, choras, intransablemente feministas... Somos... un insulto a la sociedad patriarcal. Aparecimos para quedarnos, para irrumpir repentinamente, desenmascarar las injusticias, develar los absurdos, denunciar las contradicciones, los sinsentidos, los atropellos del sexismo... para burlar los lineamientos, los patrones, los fundamentos y fundamentalismos del capitalismo neoliberal y de su orden patriarcal... horadar desde los márgenes y las brechas del machismo... desestabilizar desde el ocultamiento, desde identidades creadas y prestadas, para revelar mejor los rasgos de las desigualdades de sexo y de las construcciones de género, las violencias materiales y simbólicas que están en cada esquina, en cada 
escalera, en cada pasaje y en cada rincón de nuestro puerto...”. Así, no sólo en las capitales sigue gestándose esa desobediencia creativa que sigue renovando esta relación entre arte, política y activismo en América Latina. Todxs y muchxs más artistas visuales feministas marcan escena en lo público-físico y en lo público de la virtualidad de la red de Internet.

Foto 5. Las Choras del Puerto en acción frente al Ministerio de Salud en Santiago de Chile en mitin por prohibición de la pastilla de emergencia en Chile (2008)

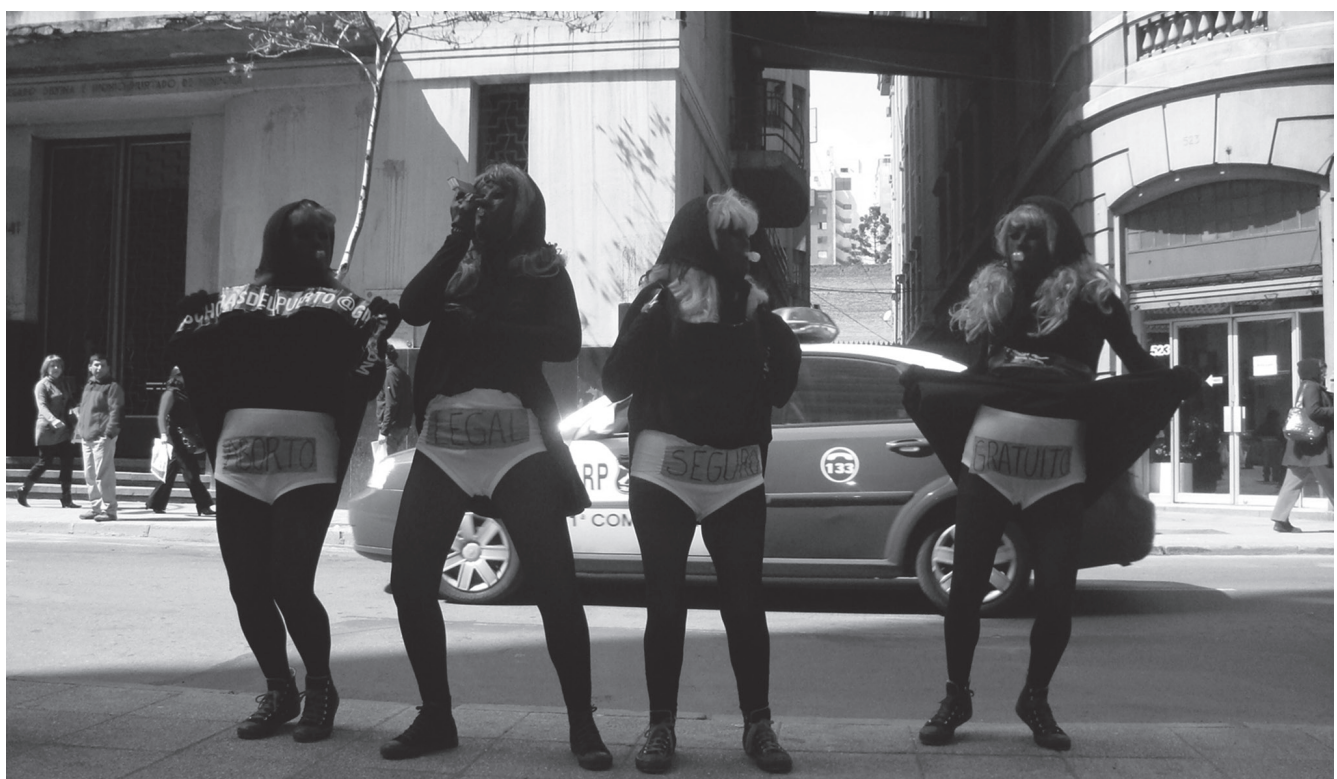

Fotografía: Julia Antivilo

\section{¿CUÁL ES LA PROBLEMÁTICA DE LAS PRÁCTICAS Y VISUALIDADES FEMINISTAS? ${ }^{7}$}

El arte feminista es la resignificación del espacio subalterno desde el cual artistas han expresado su creación cultural para convertirlo en un espacio de subversión política. Por ello, toman el cuerpo como materia prima, herramienta y medio de su

6. Ver en http://laschorasdelpuerto.blogspot.com

7. Así llamó Mary Kelly, artista y teórica feminista estadounidense, a una conferencia donde se le pidió que respondiera a la pregunta: ¿Qué es arte feminista? Ella respondió reformulando la pregunta, pues más bien habría que preguntarse ¿Cuál es la problemática de las prácticas culturales feministas? Creemos que esa es finalmente la cuestión (Pollock, 1998:10). 
arte. También como medio, lxs artistas feministas han revalorizado las artesanías, manualidades o labores de aguja. Como temas han abarcado lo doméstico, la maternidad, el deseo, entre varios más, con la meta de deconstruir lo femenino con sus cargas patriarcales que engloban las evidencias de la dominación, es decir, los imaginarios sociales y culturales que nos relacionan ya sea con lo débil, sensible, lo bueno si sigue el camino de la maternidad asexuada o la autocensura, y con lo malo si no toma tal camino. A lo largo de la historia han existido varios tipos de mujeres, como las subordinadas que no cuestionan su vida y ayudan a reproducir tal condición. Otras sí han cuestionado ese statu quo, pero no han actuado en su contra. Otrxs han sido las que intentan, creativamente, no jugar el juego construido para ellxs, haciendo de su experiencia una acción de rebeldía. En esa acción están las que no se dicen feministas y las que sí.

Podemos decir que las acciones u obras de arte que reconocen una posición crítica ante la manera de enfrentarse a la construcción violenta de los géneros constituyen una acción feminista siempre y cuando sus creadorxs se reconozcan a sí mismas con esta forma de pensar y actuar.

El posicionamiento político-ideológico que asumen lxs artistas con respecto a sus obras se inscribe en el cuestionamiento de "¿qué plasmo en la obra? ¿Qué produzco? ¿Para qué lo hago? y ¿para quiénes?”. En el "qué plasmo” estarían las obras como materialización de las experiencias. En el "qué produzco" están las autorrepresentaciones e imágenes construidas que queremos poner en cuestión, y en el "para qué" está la necesidad de deconstruir nuestros grilletes del género. Finalmente, frente a la pregunta de "para quiénes se hace esta producción" se podría responder que para los que quieran desarrollar una visión crítica de su situación de opresión de género con el propósito de revertirla.

En muchas expresiones del arte feminista latinoamericano, la creación colectiva es fundamental en tanto lógica de acción, ya que -como pocos movimientos socialeslogra una relación creativa con su práctica político-estética y cultural. El arte feminista emergió como una invitación a deconstruir lo culturalmente construido a partir de la diferencia sexual para crear otras visualidades y autorrepresentaciones. Además es una invitación para revalorizar nuestras propias experiencias y subvertirlas en contra de la discriminación y politizarlas estéticamente. A lxs artistas feministas nos interesa transformar nuestras experiencias y discursos estéticos visuales constituyendo políticas de autorrepresentación.

\section{DE LO PERSONAL ES POLÍTICO AL CUERPO ES POLÍTICO}

La emergencia de las visualidades feministas transformó el lema "Lo personal es político" en "El cuerpo es político". A partir de ahí es que cabe preguntarse: ¿qué 
significados produce la práctica artística? y ¿desde dónde encarna literalmente sus discursos y prácticas? Con estas preguntas nos aproximamos a esta práctica política y estética del arte en América Latina que, como ya hemos descrito, tiene como característica esencial encarnar un arte donde el cuerpo es herramienta, materia prima y producto.

El cuerpo como herramienta es el soporte donde se plasma la obra, así lo vemos en innumerables piezas de estas artistas. Herramienta que se dispone en la tela o en el papel de grabado en artistas como Susana Campos, Patricia Torres, Carla Rippey o Nunik Sauret; también está presente en el registro fotográfico de Yolanda Andrade, Graciela Iturbide, en la materialidad histérica y placentera de la cinética escultórica de Feliza Bursztyn, entre otras muchas más. En la utilización del cuerpo propio encontramos destacadas trayectorias de las mexicanas Maris Bustamante, Mónica Mayer, Jesusa Rodríguez o la colombiana María Teresa Hincapié, entre muchas más; o en la autorepresentación del cuerpo propio se nos hace presente la obra "Siluetas" de la cubana Ana Mendieta, o algunas series fotoperformances de las chilenas de Malignas Influencias, la mexicana Lourdes Grobet y/o los videos de Pola Weiss (México) y Alejandra Dorado (Bolivia). Como materia prima, el cuerpo es lo explorado y explotado, lo que podemos apreciar, desde Argentina, en las acciones pornoterroristas de Leonor Silvestri y el habla de insolentes lenguas de libertad sexual de la colombiana Nadia Granados, "La Fulminante". Como producto, el cuerpo es lo que se quiere cambiar, transformar, una cuestión que pretende la mayoría de las propuestas feministas que posicionan o ponen, literalmente, el cuerpo con vistas a su política estética.

Para las teóricas e historiadoras feministas, las representaciones que hacen lxs artistas feministas se muestran como un fértil campo de análisis para develar que con este arte proponen visualidades disidentes de esta cultura patriarcal, y al hablar desde sus vivencias y biografías configuran una mirada desde experiencias similares que están mediatizadas a través de un cuerpo propio y otro. Por lo tanto, podemos develar otra lectura, otra narrativa.

A partir de esta certeza, creo que es importante responsabilizar a los y las lectoras de este artículo respecto a las visualidades que hacemos de este cuerpo político otro en lucha. En particular, me gustaría referirme a cómo hacernos cargo cuando le ponemos el cuerpo a la problemática de la violencia, por ejemplo.

Desde mi opinión personal, que es política, no considero justo o ético que tengamos que volver a violentar con nuestras imágenes producidas para convocar a esa representación o autorrepresentación, pues de esas ya tenemos circulando todos los días en los medios de comunicación que encarnan las escabrosas cifras de la violencia de género y sexual. Por ello, creo que intervenir, proponer, crear, presentar otras imágenes o representaciones de nosostrxs en todos los ámbitos 
nos urge para incidir en cómo queremos ser vistas, ya no nos queremos ver más muertas, porque "VVivxs nos queremos!", lema que ya lleva años acompañándonos desde muchas trincheras en la resistencia contra la violencia machista. Un ejemplo son las Mujeres Grabando Resistencias, grupo de grabadoras mexicanas que han desarrollado dos campañas bajo este lema para la producción de grabados que se han repartido por todo el mundo. En ambas campañas las imágenes son todas de luchas vivas.

Fotos 6, 7 y 8. Registro de la acción feminista de pegar la campaña "Vivas nos queremos" en Montreal, Canadá, 2015
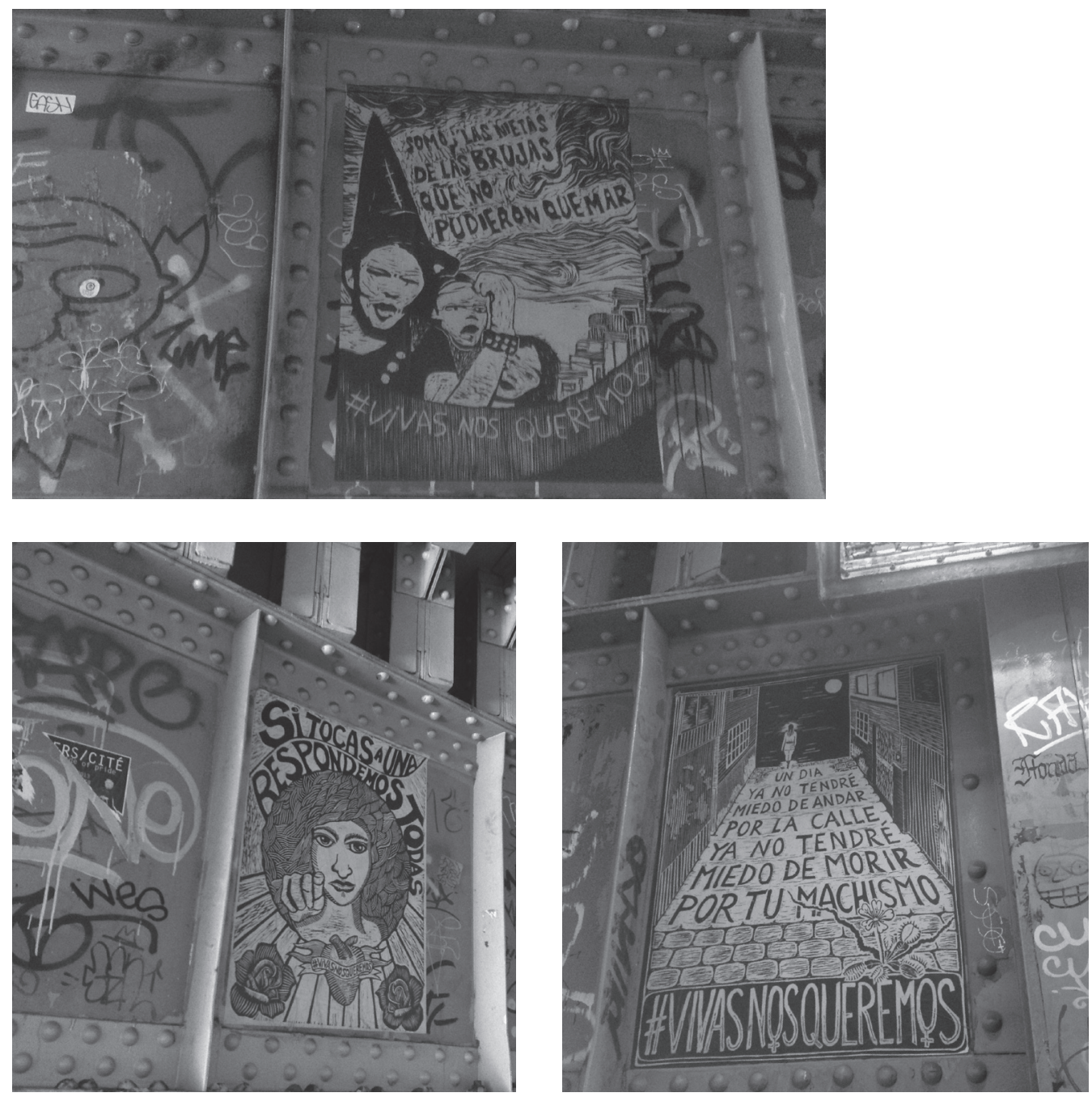

Fotografías: Marik Boudreau 
El 24 de abril del 2016 se convocó a una gran manifestación en la Ciudad de México contra los feminicidios. Comenzó en el corazón de Ecatepec, municipio feminicida del Estado de México, y desde ahí se llegó al centro de la ciudad. Muchos contingentes feministas acompañaron la manifestación. Miles de feministas ocuparon la ciudad y el transporte público, además de caravanas de autos, bicicletas, camiones, camionetas y buses. La consigna que más se escuchó, aparte del llamamiento de "¡Ni una más!", fue "Machete al machote”, poniendo en la discusión la necesidad del reconocimiento de la autodefensa como acción legítima ante la situación crítica que se vive en México.

Fotos 9 y 10. 24 de abril del 2016, Ciudad de México.

Foto Producciones y Milagros, Agrupación Feminista

A. C.
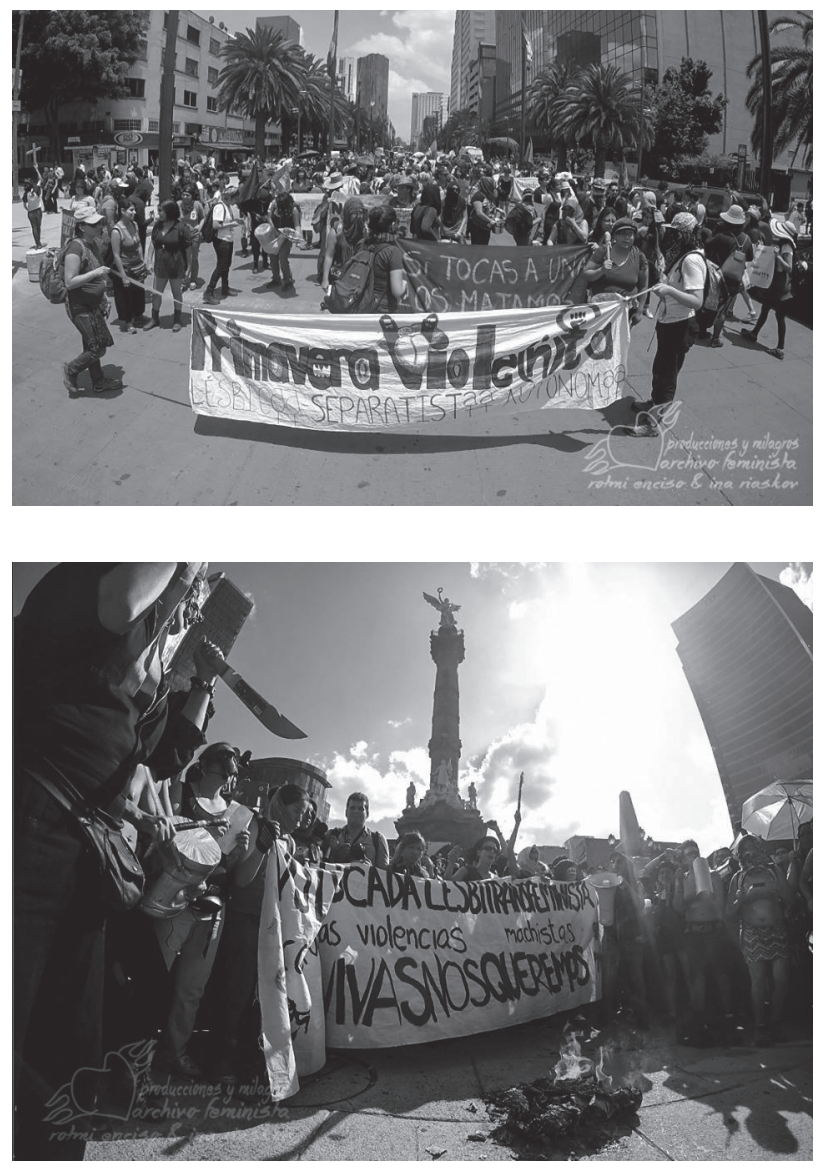


\section{Foto 11. Isabel Pliego. $24 \mathrm{~A}$}

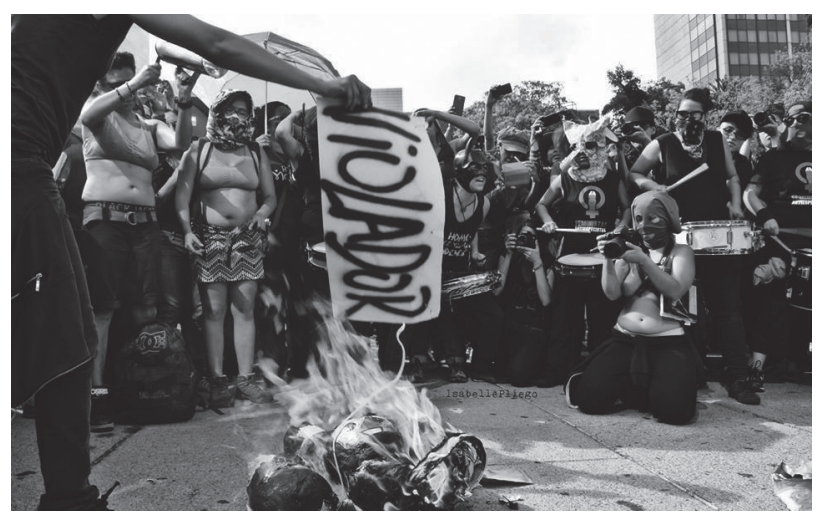

Actualmente, la lucha por el aborto en Argentina ha movilizado a muchas feministas a lo largo del país. En Buenos Aires, multitudinarias han sido las movilizaciones de la marea verde que también se ha agolpado por intensas horas ocupando las afueras y las calles aledañas al Congreso Nacional mientras se debatía la ley. Esta lucha arde en las calles con acciones como las de la colectiva artivista feminista ARDA, que a través de coreografías y lemas a viva voz resuenan en cada protesta.

Foto 12. Colectiva artivista feminista ARDA en acción

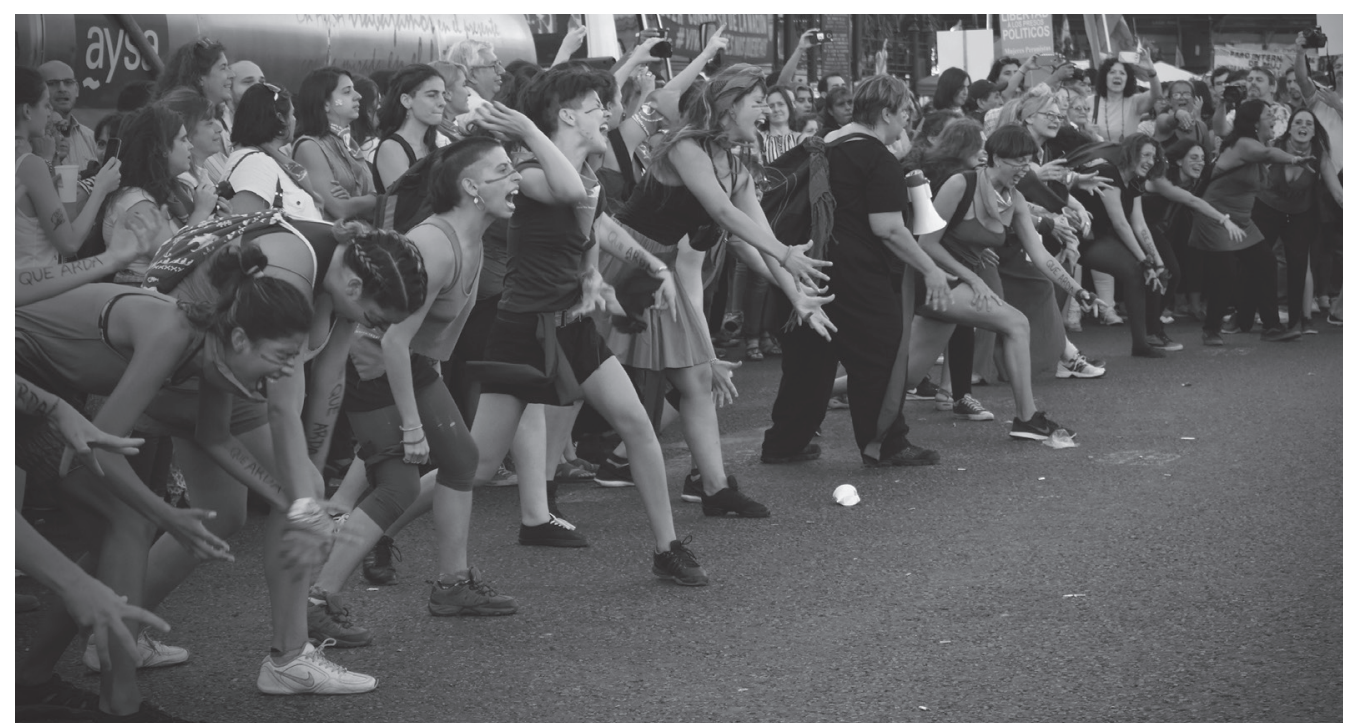

Fotografía: Romi Luna 
Hoy también se vive un fenómeno que yo personalmente nunca pensé que estaría viva para ver, aunque sea emocionada desde la distancia: el tsunami feminista en Chile, que comenzó con las estudiantes de la Universidad Austral que paralizaron y tomaron su casa de estudios hartas de las denuncias de acoso de profesores y estudiantes, y de que las autoridades académicas no prestaran atención a tal problemática. Como es un problema que se vive día a día en muchas universidades del país, este movimiento se propagó y ha durado meses, en los cuales no sólo las estudiantes universitarias se han tomado o han parado sus escuelas sino que también han participado las académicas, como por ejemplo la Red Amanda Labarca de Académicas de la Universidad de Chile. Las estudiantes secundarias también se han movilizado contra el sexismo en la educación, haciendo denuncias contra los compañeros de liceos emblemáticos de la capital por su machismo. Anterior a este fenómeno estudiantil feminista se han posicionado muy bien en los medios de comunicación las protestas del movimiento "Ni una menos", que ha sido incansable en la lucha contra la violencia machista no sólo en Chile sino también en Argentina, Uruguay, Paraguay, Ecuador, Perú, Bolivia, Colombia, Venezuela, además de España e Italia.

Foto 13. Dibujo digital de María María Acha-Kutscher, de la Exposición INDIGNADAS/ Latinoamérica. Manifestación en Santiago de Chile en contra de la violencia machista y a favor de una educación no sexista. 16 de mayo de 2018. Dibujo creado a partir de una imagen de prensa de BBC Mundo

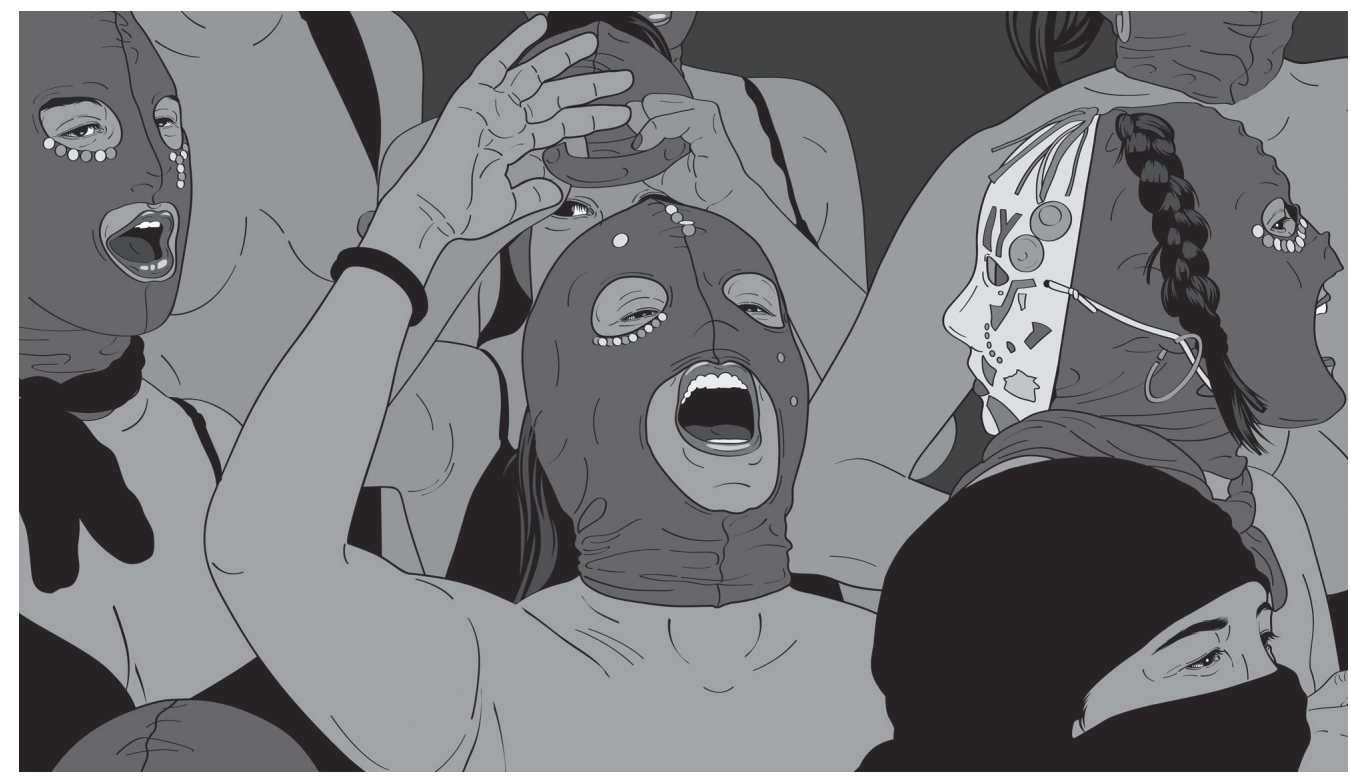

Fotografía: Rodrigo Abd/TT 
Foto 14. Dibujo digital del Plantón SOMOS 2074 Y MUCHAS MÁS para exigir a la Fiscalía peruana que denuncie por crímenes de lesa humanidad a los responsables de las esterilizaciones forzadas, cuyas víctimas son mujeres campesinas quechua hablantes.

Lima, 2016

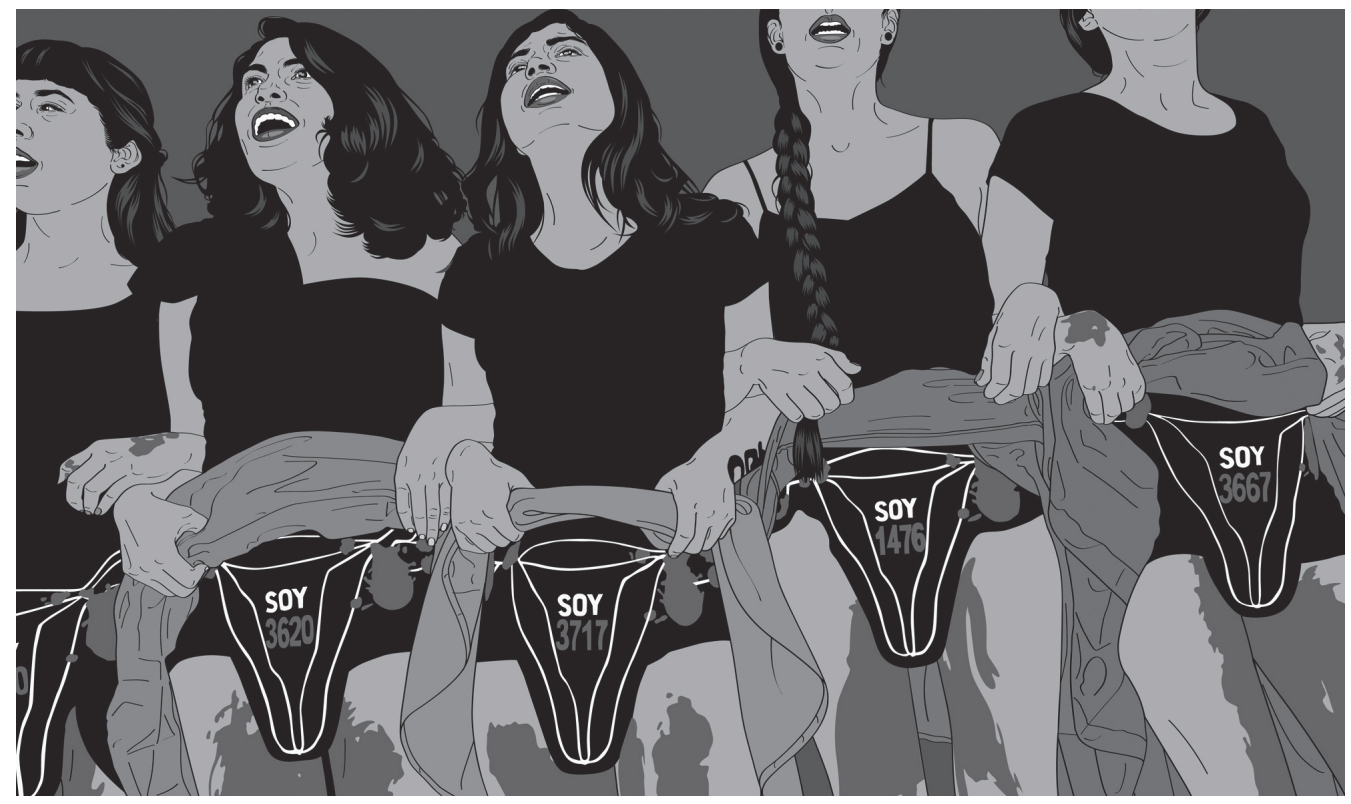

Foto 15. MARCHA DE LAS PUTAS. Brasil, 2016

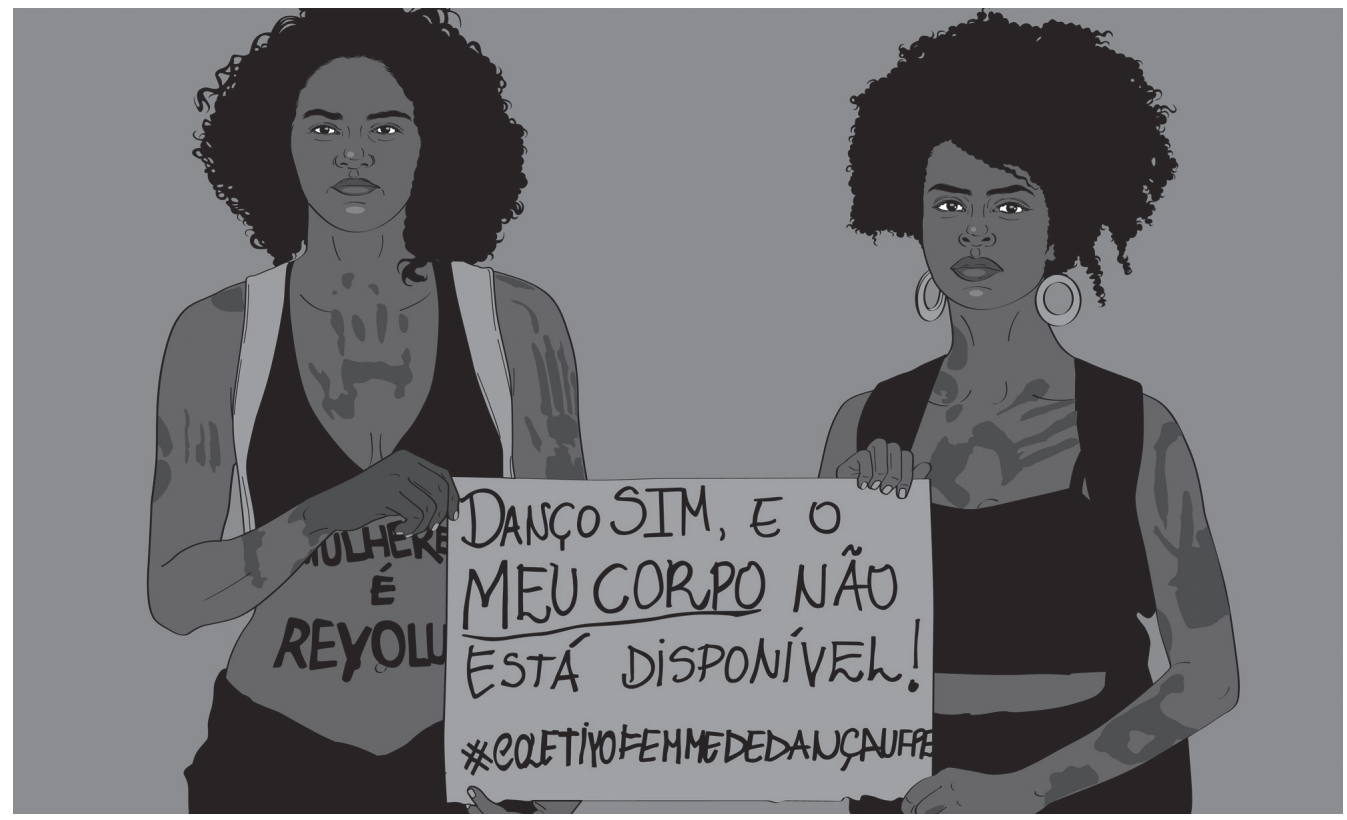


La MARCHA DE LAS PUTAS (SLUTWALK) es un movimiento de protesta feminista global, cuyo objetivo es disipar el mito de que las víctimas de asalto sexual tienen la culpa debido a su vestimenta, consumo de alcohol o historial sexual. SLUTWALK también se apropia del término despectivo "puta" para reducir su poder. El movimiento comienza en Canadá en 2011, como reacción a las declaraciones de un oficial de policía, Michael Sanguinetti, quien sugirió en una clase de seguridad en la Universidad de York "que las estudiantes podrían evitar una agresión sexual si no se vistiesen como putas". Heather Jarvis y Sonya Barnett organizaron la primera marcha y muchas mujeres participaron en ella vestidas de "zorras". Dibujo digital creado a partir de una fotografía de Marciojcgomes.

Foto 16. Movimiento MARCHA DE LAS PUTAS (SLUTWALK) para protestar en contra de la discriminación y la violencia contra las mujeres. Mayo 31 de 2014, Bogotá, Colombia. Dibujo digital creado a partir de una imagen de prensa de NOTICIAS 24

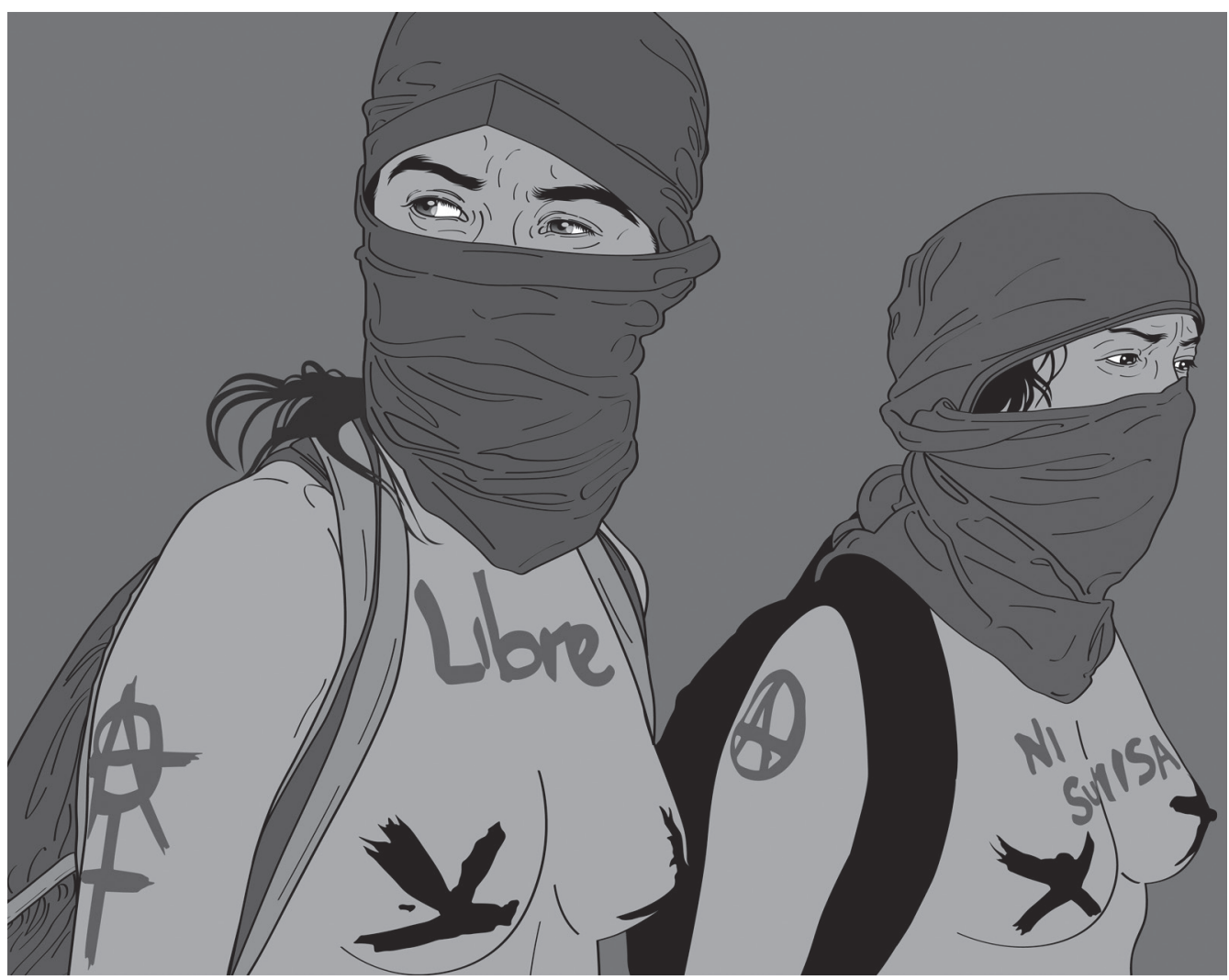

Fotografía: AFP/Eitan Abramovich 
Foto 17. Marcha para protestar contra el archivamiento de la ley de despenalización del aborto. Noviembre de 2015, Lima. Dibujo digital creado a partir de una imagen de prensa de LA REPÚBLICA

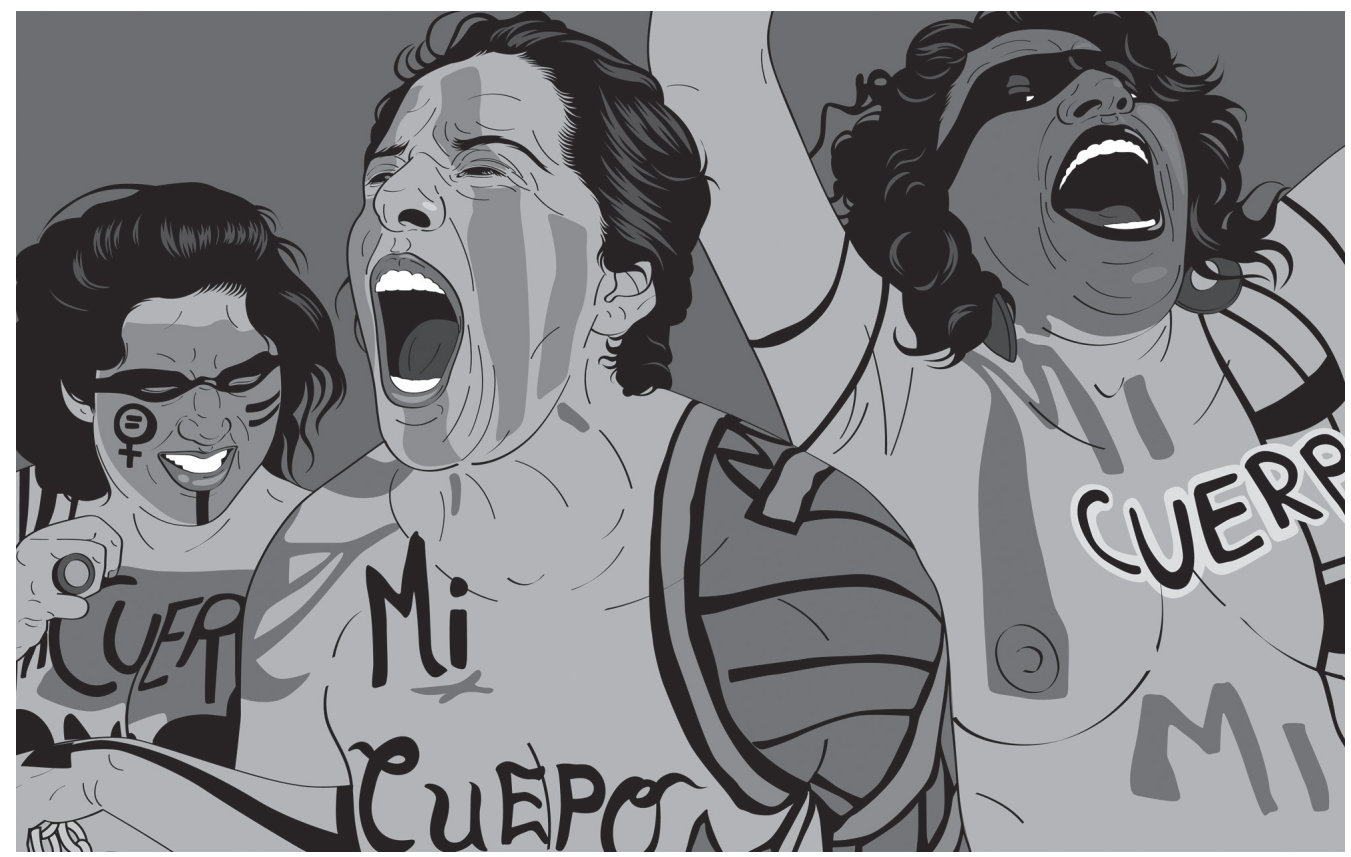

Fotografía: Renato Pajuelo

Quisiera cerrar con una pregunta: ¿por qué causa tanto revuelo y respuestas violentas en la opinión pública la forma en que ponen el cuerpo las feministas a la protesta? ¿Por qué no les molestan los pechos desnudos de la TV y sí los que se alzan en la protesta callejera? Es lamentable toda la violencia desatada contra el movimiento que transita rebelde la región. Inclusive ha sido objeto de censura en espacios de arte, como por ejemplo la exposición INDIGNADAS/Latinoamérica de la artista peruana María María Acha-Kutscher, a quien después de varios cambios de fechas, le cancelaron la muestra que presentaría en la Galería Abierta de la Municipalidad de Miraflores en Lima. Bajo los argumentos de que las imágenes eran "duras” y que "al estar en período electoral hay que tener el máximo cuidado con los contenidos de las propuestas", se canceló la muestra INDIGNADAS, que son estas series de dibujos que ilustran estas últimas líneas, que realizó la artista a partir de fotografías de las movilizaciones feministas en diferentes países de América Latina. A través de las redes sociales, la artista contestó a la censura: "¿Llaman imágenes duras a aquellas donde aparecen mujeres de toda la región latinoamericana manifestándose por sus derechos? ¿Duras? Duro es que durante el gobierno de Alberto Fujimori 
se haya llevado a cabo una política de esterilizaciones forzadas a mujeres de zonas rurales, para reducir la población indígena del Perú. Duro es que violen y dejen embarazadas a niñas de 10 años, y encima no les permitan abortar. Duro es que en los últimos años cientos de mujeres hayan sido violentadas y asesinadas por sus parejas o exparejas. Duro es que cada día haya feminicidios en toda Latinoamérica, es decir, que cada año miles de mujeres sean asesinadas por el solo hecho de ser mujeres. Duras son la feminización de la pobreza, la esclavitud sexual y la impunidad en que vivimos las mujeres. Eso es duro señoras y señores y esto es lo que debería aparecer como primordial y urgente en la agenda electoral"s. A la última edición de este artículo la Galería Abierta revocó la idea de no presentar la exposición INDIGNADAS tras la fuerte presión mediática de descontento frente al acto de censura que recorrió diferentes medios y redes sociales.

\section{PALABRAS PARA CERRAR}

Con todo, nos encontramos con otro tipo de narratividad y autorrepresentación que propone deconstruir los patrones culturales que se develan a través de las construcciones de imaginarios y representaciones responsables de la perpetuidad de la mirada androcéntrica y sexista del mundo. Subvertir el esquema de representación de la cultura hegemónica, o sea, el cómo se nos ve -y por ello, se nos trata- en parte es lo que define las prácticas de las artistas visuales feministas que llevan más de cuatro décadas en el proceso vindicativo de levantarla voz para la autorrepresentación a partir de una mirada propia de su alteridad subjetiva. Las visualidades feministas siguen desafiando las representaciones dominantes y estereotipadas de la construcción de los géneros para reinventar una forma más libre de ser fuera de la mirada patriarcal, para cuestionarla y patentar sus entrelazamientos con las problemáticas de género, sexo y raza.

8. Ver en https://www.facebook.com/mariamaria.acha/mediaset?set=a.446666815805440.10737 41831.100013863764554\&type $=3$ revisado el 15 de julio de 2018. 


\section{REFERENCIAS}

ANTIVILO, Julia. Entre lo sagrado y lo profano se tejen rebeldias. Arte feminista latinoamericano. Ed. Desde Abajo, Colombia, 2015.

CEJAS, Mónica (coordinadora). Feminismo, cultura y política. Prácticas irreverentes. Ed. ITACA y UAM Xochimilco, México, 2016.

Fontán, Clara: María Luisa Bemberg, Buenos Aires, Centro Editor de América Latina e Instituto Nacional de Cinematografía, 1993.

GALINDO, María. Feminismo urgente. A despatriarcar!. Ed. Lavaca. Bolivia, 2013.

Gargallo, Francesca. Las ideas feministas latinoamericanas. Ed. Desde Abajo, Bogotá, 2004.

MANDEL, Claudia. Estéticas del borde. Prácticas y violencia contra las mujeres en Latinoamérica. Ed. UCR, Costa Rica, 2016.

Mirzoeff, Nicholas. Una introducción a la cultura visual. España, Ed. Paidós, 2003.

Pollock, Griselda. Vision and difference. Feminity, feminism and the histories of art. Ed. Routledge, Londres y Nueva York, 1998.

Rosa, María Laura. Legados de libertad. El arte feminista en la efervescencia democrática. Ed. Biblios, Argentina, 2014.

-: "El acto de perpetuar el presente. Femimundo de María Luisa Bemberg y la construcción del ángel del hogar". Esta ponencia fue presentada en las III Jornadas de Historia, Género y Política en los ‘70, organizadas por el Instituto Interdisciplinario de Estudios de Género de la Facultad de Filosofía y Letras de la Universidad de Buenos Aires y el Museo Roca. 22, 23 y 24 de septiembre, Buenos Aires, 2010. 